\title{
CULTIVARES DE MILHO EM DIFERENTES POPULAÇÕES DE PLANTAS COM ESPAÇAMENTO REDUZIDO NA SAFRINHA
}

\author{
JOSÉ SALVADOR SIMONETI FOLONI ${ }^{1}$, JULIANO CARLOS CALONEGO ${ }^{2}$, TIAGO ARANDA \\ CATUCHI $^{3}$, NORBERTO ADRIAN BELLEGGIA ${ }^{4}$, CARLOS SÉRGIO TIRITAN ${ }^{2}$ e ALEXANDRIUS \\ DE MORAES BARBOSA ${ }^{3}$
}

\author{
${ }^{1}$ Embrapa Soja, Londrina, PR, Brasil, salvador.foloni@embrapa.br \\ ${ }^{2}$ Unoeste, Presidente Prudente,SP,Brasil,juliano@unoeste.br, tiritan@unoeste.br \\ ${ }^{3}$ Unesp, Botucatu,SP,Brasil,tiagocatuchi@hotmail.com, alexandriusmb@yahoo.com.br \\ ${ }^{4}$ Sementes Rancharia LTDA, Rancharia,SP,Brasil, adrian@sementesrancharia.com.br
}

$\overline{\text { Revista Brasileira de Milho e Sorgo, v.13, n.3, p. 312-325, } 2014}$

\begin{abstract}
RESUMO - O objetivo do trabalho foi avaliar o comportamento de diferentes cultivares de milho safrinha em função da variação da população de plantas em espaçamento reduzido. Foram realizados dois experimentos, o primeiro na safrinha de 2005 no município de Atalaia, PR (Exp1), e o segundo na safrinha de 2007 em Alvorada do Sul, PR (Exp2). Ambos foram conduzidos no espaçamento de $0,45 \mathrm{~m}$ sob sistema plantio direto (SPD) em sucessão à soja. Nos dois experimentos, adotou-se o delineamento experimental em blocos completos ao acaso, com quatro repetições, sendo empregado no Exp1 o esquema fatorial 2x4 e no Exp2 o fatorial 4x4, da seguinte forma: (1) Exp1: cultivares de milho AG 9010 e DKB 979 instaladas com quatro populações: 39.000, 52.000, 79.000 e 105.000 plantas ha' ${ }^{-1}$; e (2) Exp2: cultivares AG 9010, DKB 350, Maximus e Impacto instaladas com quatro populações: 39.000, 52.000, 79.000 e 105.000 plantas ha $^{-1}$. A cultivar AG 9010 respondeu significativamente ao aumento da população de plantas somente no Exp 1, atingindo máximas produtividades com cerca de 70 a 80 mil plantas ha-1. A cultivar DKB 979 apresentou maior produtividade quando cultivada com cerca de 70 a 75 mil plantas ha ${ }^{-1}$. As cultivares DKB 350, Maximus e Impacto não toleram aumento populacional de plantas, necessitando manter a recomendação tradicional de 45 a 55 mil plantas ha- ${ }^{-1}$. As cultivares Maximus e Impacto apresentaram maiores índices de acamamento de plantas com o aumento populacional.
\end{abstract}

Palavras-chave: Zea mays; arranjo espacial de plantas; densidade de planta; estande da cultura; milho de segunda época

\section{HIGH PLANT POPULATION OF CORN WITH REDUCED ROW SPACING IN SECOND SEASON}

\begin{abstract}
The aim of this study was to evaluate the performance of different maize cultivars due to the variation in plant population in reduced row spacing. Two experiments were conducted, the first off-season in 2005 in the municipality of Atalaia, PR (Exp1), and the second off-season in 2007 in the municipality of Alvorada do Sul, PR (EXP2). Both were conducted in crops managed under no-tillage system after crop soybean using $0.45 \mathrm{~cm}$ row spacing. The randomized complete block design with four replications was adopted in two experiments (Exp 1 and Exp 2). In Exp 1 the factorial design 2x4 was used (two maize cultivars, AG 9010 and DKB 979 installed with four populations: 39,000, 52,000, 79,000 and 105,000 plants $\mathrm{ha}^{-1}$ ). In Exp2 the 4x4 factorial design was used (four maize cultivars, AG 9010, DKB 350, Impact and Maximus and four populations, 39,000, 52,000, 79,000 and 105,000 plants ha ${ }^{-1}$ ). The Cultivar AG 9010 responded significantly to the increased plant population only in Exp 1, reaching maximum yield of about 70-80 thousand plants ha $^{-1}$. The DKB 979 cultivar showed highest yield when grown with about 70-75 thousand plants ha ${ }^{-1}$. The DKB 350, Maximus and Impact cultivars cannot tolerate higher population of plants, with better performance using the traditional recommendation of 45-55 thousand plants $\mathrm{ha}^{-1}$. Impact and Maximus cultivars presented higher plant lodging with the population increase.
\end{abstract}

Key words: Zea mays; spatial plant; plant density stand of crop; off-season corn. 
Em determinadas regiões do Brasil, há viabilidade para o cultivo do milho de segunda época (comumente denominado de safrinha), tais como no Norte e no Oeste do Paraná. De acordo com a Conab (2013), no ano agrícola de 2011/2012, foram cultivados cerca de 3 milhões de hectares de milho nas lavouras paranaenses, dos quais 2,02 milhões na safrinha, com produtividade média de $5.026 \mathrm{~kg}$ $\mathrm{ha}^{-1}$ de grãos, e 0,98 milhão de hectares na safra de verão, com produtividade média de $6.729 \mathrm{~kg} \mathrm{ha}^{-1}$. Nota-se, portanto, elevada evolução socioeconômica e tecnológica do milho safrinha.

A população de plantas é um dos principais fatores que influem na capacidade da lavoura em captar recursos do ambiente (água, luz e nutrientes). Tal atributo é particularmente importante para culturas anuais, pois pode ser ajustado safra a safra em razão de diferentes interações entre genótipo e ambiente de produção (Lloveras et al., 2004).

O espaçamento entre fileiras da lavoura, por sua vez, guarda forte relação com o arranjo espacial entre plantas, sendo passível de ajuste com o intuito principal de reduzir a competição intraespecífica. No que diz respeito às limitações tecnológicas, argumenta-se que a modernização do maquinário vem permitindo maiores variações de espaçamento entre fileiras nas lavouras, possibilitando novas recomendações de arranjos espaciais e populações de plantas, com avanços significativos na exploração dos genótipos em interação com o ambiente e manejo (Dourado Neto et al., 2003; Cruz et al., 2007).

Quando reduz-se o espaçamento entre fileiras da cultura, surgem outras vantagens potenciais além da capacidade produtiva, a saber: (1) cobertura mais rápida do solo para supressão de plantas daninhas e menor tempo de exposição do solo à erosão no início do desenvolvimento da cultura;
(2) menor quantidade depositada de fertilizante por metro de sulco de semeadura lavoura, minimizando problemas de toxicidade/salinidade sobre sementes e plântulas; (3) maior uniformidade de deposição de calda de pulverização sobre o dossel da lavoura; e (4) maior praticidade no manuseio de semeadoras nos sistemas de cultivo de soja e milho safrinha, pois ambas as culturas podem ser instaladas com o mesmo espaçamento (Balbinot Junior \& Fleck, 2005; De-Maria \& Ramos, 2007).

O surgimento de novas cultivares também tem possibilitado a redução do espaçamento entre fileiras e o aumento da população de plantas nas lavouras de milho no Brasil, pois há opções de genótipos mais precoces, com menor estatura de plantas, com folhas mais eretas e dossel mais compacto (Cruz et al., 2007). Em geral, as cultivares de milho que apresentam folhas mais eretas e ciclo precoce são mais propícias ao adensamento de plantas, podendo favorecer o rendimento de grãos na safrinha (Piana et al., 2008).

Nesse contexto, relata-se que, em programas de melhoramento de milho no Brasil, tem-se buscado genótipos com elevada resposta produtiva em espaçamentos reduzidos associados a elevadas populações de plantas (Dourado Neto et al.,2003). Enfatiza-se que o fato das cultivares mais precoces necessitarem de maiores populações de plantas para expressar o seu máximo potencial produtivo por área, em comparação às de ciclo mais tardio, esteja relacionado principalmente ao porte e à arquitetura de plantas (Sangoi et al., 2002; Amaral Filho et al., 2005).

Em amplo estudo sobre milho safrinha no Brasil, Cruz et al. (2010) avaliaram 345 lavouras comerciais nos estados de São Paulo, Paraná e em diferentes regiões do Centro-Oeste e constataram que, em $37 \%$ dos casos, o milho safrinha foi 
conduzido com espaçamento reduzido, da ordem de 0,45 a 0,50 m entre linhas. Contudo, no que se refere à população de plantas, são recorrentes as argumentações sobre a forte interação entre genótipo e ambiente (Sangoi et al., 2002; Amaral Filho et al., 2005 Strieder et al., 2007; Cruz et al., 2010).

Em estudo com cultivares de milho de diferentes arquiteturas de planta, Strieder et al. (2007) concluíram que a produtividade de grãos de genótipos de folhas eretas aumentou em função do aumento da população de plantas, independentemente do espaçamento utilizado. Já em híbridos de milho de folhas decumbentes, a produtividade de grãos não é afetada pela densidade de plantas, independente do espaçamento entre fileiras adotado.

O objetivo do trabalho foi avaliar o desempenho de diferentes cultivares de milho em função da variação da população de plantas, adotando-se o espaçamento entre fileiras reduzido de $0,45 \mathrm{~m}$ no ambiente de safrinha em duas localidades do Norte do Paraná.

\section{Material e Métodos}

Foram realizados dois experimentos: o primeiro na safrinha de 2005 no município de Atalaia, PR (Exp1); e o segundo na safrinha de 2007 em Alvorada do Sul-PR (Exp2). Ambos foram conduzidos em lavouras manejadas no sistema plantio direto (SPD), que vinham sendo ocupadas por mais de cinco anos consecutivos com a sucessão de culturas soja/milho safrinha. A localização do Exp1 foi a 23o 25 ' 32" Sul, 52 05' 45" Oeste e $686 \mathrm{~m}$ de altitude e a do Exp2 a 22o 49' 25" Sul, 51o 14' 18" Oeste e $403 \mathrm{~m}$ de altitude. O solo do Exp1 foi classificado como Latossolo Vermelho Distroférrico de textura média e o do Exp2 como Latossolo Vermelho
Eutroférrico de textura argilosa (Embrapa, 2006). O clima de ambas as localidades é do tipo Cfa, conforme Köppen, que se caracteriza como subtropical úmido, com verões quentes e chuvosos, geadas pouco frequentes e sem estação seca definida.

Os dados climáticos locais foram coletados durante a condução dos experimentos e estão apresentados na Figura 1. Foram realizadas amostragens do solo na camada de $0-20 \mathrm{~cm}$ de profundidade para caracterização de atributos químicos e granulometria, com os seguintes resultados: (1) Exp1 com pH de 5,2 ( $\left.\mathrm{CaCl}_{2} 0,01 \mathrm{~mol} \mathrm{l}^{-1}\right) ; 21 \mathrm{~g} \mathrm{dm}^{-3}$ de $\mathrm{MO} ; 20,5$ $\mathrm{mg} \mathrm{dm}{ }^{-3}$ de Presina; $24 \mathrm{mmol}_{\mathrm{c}} \mathrm{dm}^{-3} \mathrm{de} \mathrm{H}+\mathrm{Al} ; 2,7$ $\mathrm{mmol}_{\mathrm{c}} \mathrm{dm}^{-3}$ de K; $29 \mathrm{mmol}_{\mathrm{c}} \mathrm{dm}^{-3}$ de $\mathrm{Ca} ; 13 \mathrm{mmol}_{\mathrm{c}}$ $\mathrm{dm}^{-3}$ de $\mathrm{Mg} ; 44,7 \mathrm{mmol}_{\mathrm{c}} \mathrm{dm}^{-3}$ de SB; $69 \mathrm{mmol}_{\mathrm{c}}$ $\mathrm{dm}^{-3}$ de CTC; saturação por bases de $65 \% ; 596,1 \mathrm{~g}$ $\mathrm{kg}^{-1}$ de areia; $179,8 \mathrm{~g} \mathrm{~kg}^{-1}$ de silte e 223,5 $\mathrm{g} \mathrm{kg}^{-1}$ de argila; e (2) Exp2 com pH de 5,9 $\left(\mathrm{CaCl}_{2}\right.$ 0,01 mol $\left.\mathrm{l}^{-1}\right) ; 16,5 \mathrm{~g} \mathrm{dm}^{-3}$ de MO; $36 \mathrm{mg} \mathrm{dm}^{-3}$ de Presina; 38 $\mathrm{mmol}_{\mathrm{c}} \mathrm{dm}^{-3} \mathrm{de} \mathrm{H}+\mathrm{Al} ; 4 \mathrm{mmol}_{\mathrm{c}} \mathrm{dm}^{-3}$ de $\mathrm{K} ; 68 \mathrm{mmol}_{\mathrm{c}}$ $\mathrm{dm}^{-3}$ de Ca; $26 \mathrm{mmol}_{\mathrm{c}} \mathrm{dm}^{-3} \mathrm{de} \mathrm{Mg} ; 92 \mathrm{mmol}_{\mathrm{c}} \mathrm{dm}^{-3} \mathrm{de}$ soma de bases (SB); $136 \mathrm{mmol}_{\mathrm{c}} \mathrm{dm}^{-3}$ de CTC; 72\% de saturação por bases (V); $92 \mathrm{~g} \mathrm{~kg}^{-1}$ de areia; $138 \mathrm{~g}$ $\mathrm{kg}^{-1}$ de silte; $770 \mathrm{~g} \mathrm{~kg}^{-1}$ de argila.

Nos dois experimentos, adotou-se o delineamento experimental em blocos completos ao acaso, com quatro repetições, no esquema fatorial $2 \times 4$ para o Exp1 e fatorial $4 \times 4$ para o Exp2, e os tratamentos foram arranjados da seguinte forma: (1) Exp1 com as cultivares de milho AG 9010 e DKB 979 instaladas com quatro populações iniciais de 39.000, 52.000, 79.000 e 105.000 plantas ha ${ }^{-1}$; e (2) Exp2 com as cultivares de milho AG 9010, DKB 350, Maximus e Impacto instaladas com quatro populações iniciais de 39.000, 52.000, $79.000 \mathrm{e}$ 105.000 plantas $\mathrm{ha}^{-1}$. As parcelas foram constituídas por oito fileiras de $6 \mathrm{~m}$ de comprimento e a área útil 

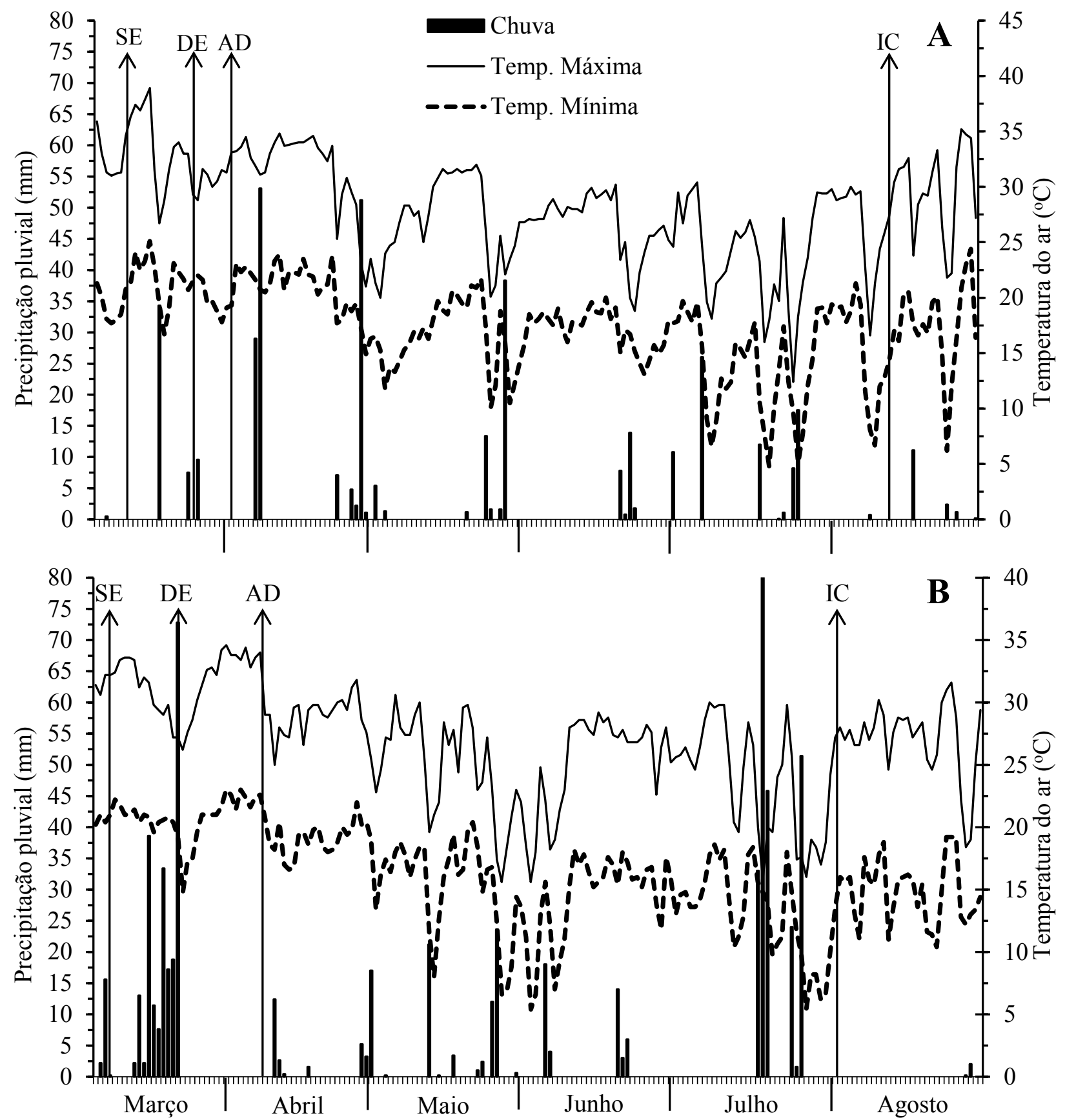

FIGURA 1. Precipitação pluvial e temperaturas máxima e mínima ocorridas no decorrer do experimento $1 \mathrm{em}$ Atalaia,PR, na safrinha de 2005 (A) e no decorrer do experimento 2 em Alvorada do Sul, PR, na safrinha de 2007 (B). SE: semeadura; DE: desbaste; AD: adubação de cobertura; IC: início da colheita. 
das mesmas foi formada pelas quatro linhas centrais, descartando-se $1 \mathrm{~m}$ de lavoura nas extremidades longitudinais.

As cultivares de milho foram escolhidas em razão do porte das plantas e do ciclo: (1) cv. AG 9010 convencional (empresa Agroceres), híbrido simples, ciclo super precoce, folhas eretas, soma térmica de 770 graus dias e altura média de plantas de 2,00 m; (2) cv. DKB 979 convencional (empresa Dekalb), híbrido duplo, ciclo precoce, folhas semi-eretas, soma térmica de 855 graus dias e altura média de plantas de 2,20 m; (3) cv. DKB 350 convencional (empresa Dekalb), híbrido triplo, ciclo precoce, folhas semi-eretas, soma térmica de 860 graus dias e altura média de plantas de 2,20 m; (4) cv. Maximus convencional (empresa Syngenta), híbrido simples, ciclo precoce, folhas normais, soma térmica de 890 graus dias e altura média de plantas de 2,47 m; (5) cv. Impacto convencional (empresa Syngenta), híbrido simples, ciclo precoce, soma térmica de 895 graus dias e altura média de plantas de 2,46 m.

Por ocasião da semeadura, fez-se a dessecação das áreas com glifosato na dose de 1,08 kg $\mathrm{ha}^{-1}$ para ambos os experimentos. Os Exp1 e Exp2 foram instalados em 11/03/2005 e 05/03/2007, respectivamente, nos quais foram utilizadas semeadoras/adubadoras desenvolvidas para o SPD, munidas de discos de corte e hastes escarificadoras, com a finalidade de demarcar as linhas e depositar o adubo nos sulcos de semeadura espaçados a $0,45 \mathrm{~m}$, com posterior deposição das sementes. No Exp1, foram aplicados $200 \mathrm{~kg} \mathrm{ha}^{-1}$ do formulado NPK 08-28-16 e, no Exp2, foram $260 \mathrm{~kg} \mathrm{ha}^{-1}$ do formulado NPK 12-15-15, com base nas recomendações de Duarte et al. (1997).

Em ambos os experimentos, foram efetuadas semeaduras manuais com o auxílio de gabaritos, utilizando-se o dobro de sementes viáveis por unidade de área, as quais foram previamente tratadas com fungicidas (60 g carboxin $+60 \mathrm{~g}$ thiram por $100 \mathrm{~kg}$ de sementes) e inseticida thiodicarb (700 g do i.a. por $100 \mathrm{~kg}$ de sementes). As diferentes densidades populacionais foram alcançadas mediante a variação do número de plantas nas linhas de lavoura. No Exp1, aos oito dias após a emergência da cultura (DAE), e no Exp2, aos 11 dias após a emergência (DAE), foram efetuados desbastes, deixando-se apenas uma única planta por distância previamente calculada.

Fizeram-se adubações nitrogenadas de cobertura a lanço em área total sobre a palhada, aos 17 DAE no Exp1 com $25 \mathrm{~kg} \mathrm{~N} \mathrm{ha}^{-1}$ (sulfato de amônio) e aos 22 DAE no Exp2 com $37 \mathrm{~kg} \mathrm{~N} \mathrm{ha}^{-1}$ (uréia). Em ambos os experimentos, fez-se o manejo de plantas daninhas em pós-emergência inicial com a pulverização do herbicida atrazina ( $2 \mathrm{~kg}$ i.a. ha $\left.{ }^{-1}\right)$. No Exp1, fez-se o manejo de lagartas desfolhadoras aos 20 DAE com a aplicação do inseticida lufenurom (15 g i.a. ha ${ }^{-1}$ ) e aos 38 DAE com deltametrina ( $5 \mathrm{~g}$ i.a. ha $^{-1}$ ). No Exp2, o milho recebeu duas aplicações de inseticida, aos 16 DAE com $104 \mathrm{~g} \mathrm{ha}^{-1}$ de metomil e aos 29 DAE com $15 \mathrm{~g} \mathrm{ha}^{-1}$ de lufenurom.

Quando 50\% das plantas encontravam-se com os pendões aparentes (florescimento), foram tomadas medidas de altura de 20 plantas ao acaso na área útil das parcelas, a partir da superfície do solo até o ponto de inserção do pendão no caule, para ambos os experimentos. No Exp1, neste mesmo estádio fenológico, determinou-se o diâmetro do caule em 20 plantas ao acaso na área útil das parcelas, tomando-se as medidas no meio do primeiro entrenó acima das raízes adventícias.

Por ocasião da colheita do milho, fez-se a contagem do número total de plantas contidas na 
área útil das parcelas e quantificou-se o número de plantas acamadas, considerando-se as que estavam com os caules inclinados em ângulo menor que $45^{\circ}$ em relação à superfície do solo, partindo do princípio que seriam problemáticas à colheita mecanizada. De posse desses dados, calcularam-se a população final de plantas e a porcentagem de acamamento da lavoura.

As colheitas do milho foram iniciadas aos 147 DAE (13/08/2005) e aos 141 DAE (02/08/2007) para os Exp1 e Exp2, respectivamente, em razão da maturação dos grãos das cultivares mais precoces e, subsequentemente, para as mais tardias. Esta operação foi realizada manualmente, na qual foram coletadas todas as espigas contidas na área útil das parcelas, que foram contadas e trilhadas. Em seguida, fez-se a pesagem dos grãos sem impurezas e amostras foram coletadas para determinação da umidade e massa de 1000 grãos. A partir desses dados, calcularam-se o número de espigas/planta e a produtividade de grãos com teor de água corrigido a $130 \mathrm{~g} \mathrm{~kg}^{-1}$.

No estudo estatístico, consideraram-se os tratamentos de cultivares como variáveis qualitativas, submetendo-os à análise de variância ( $\mathrm{p} \leq$ $0,05)$ e ao teste de Tukey $(\mathrm{p} \leq 0,05)$ para calcular a diferença mínima significativa (DMS). Foram realizadas análises de regressão em razão da variação da população inicial de plantas, nas quais foram ajustadas equações a partir da significância do coeficiente de regressão e do teste $\mathrm{F}$ da regressão (ambos a 5\% de probabilidade), em consonância com os maiores valores dos coeficientes de determinação $\left(\mathrm{R}^{2}\right)$.

\section{Resultados e Discussão}

No Exp 1, a população final de plantas foi em média $6 \%$ menor que aquelas definidas no início do experimento. Já a porcentagem de sobrevivência do Exp 2 obteve resposta quadrática, sendo que a porcentagem de sobrevivência de plantas foi menor nas maiores populações de plantas estudadas (Figura 2).

O número de espigas por planta foi reduzido de forma linear com o aumento da população de plantas, nos dois híbridos estudados no Exp 1, sendo reduzido de 1,15 para 0,85 em média. Já no Exp 2, esses mesmos materiais não apresentaram alterações no número de espigas por planta em função da população inicial, com médias de 0,93 e 0,96 espigas por planta, para o AG 9010 e o DKB 350, respectivamente. Em contrapartida, as cultivares Impact e Maximus apresentaram maior número de espigas por planta com a menor densidade populacional, tendo redução linear do número de espigas em função do aumento da população de plantas. A redução do número de espigas por planta com o aumento da densidade ocorre em razão do aumento do número de plantas dominadas na lavoura, ou seja, plantas que não produzem espigas. De acordo com Vieira Junior et al. (2006), este fato ocorre em razão do excesso de plantas e da heterogeneidade na distribuição espacial das plantas na lavoura. Calonego et al. (2011) observaram resposta similar no milho híbrido AG 1015, com o aumento da população de plantas de 45 mil para 75 mil plantas por hectare. De acordo com Fornasieri Filho (2007), esta resposta ocorre em razão de alterações morfológicas e fisiológicas que as plantas de milho podem sofrer em condições de altas densidades populacionais, resultando no desenvolvimento de plantas sem espigas.

A densidade populacional não afetou a altura das plantas de milho avaliadas no Exp1 (Figura 3A). No Exp2 (Figura 3B), apenas a cultivar 


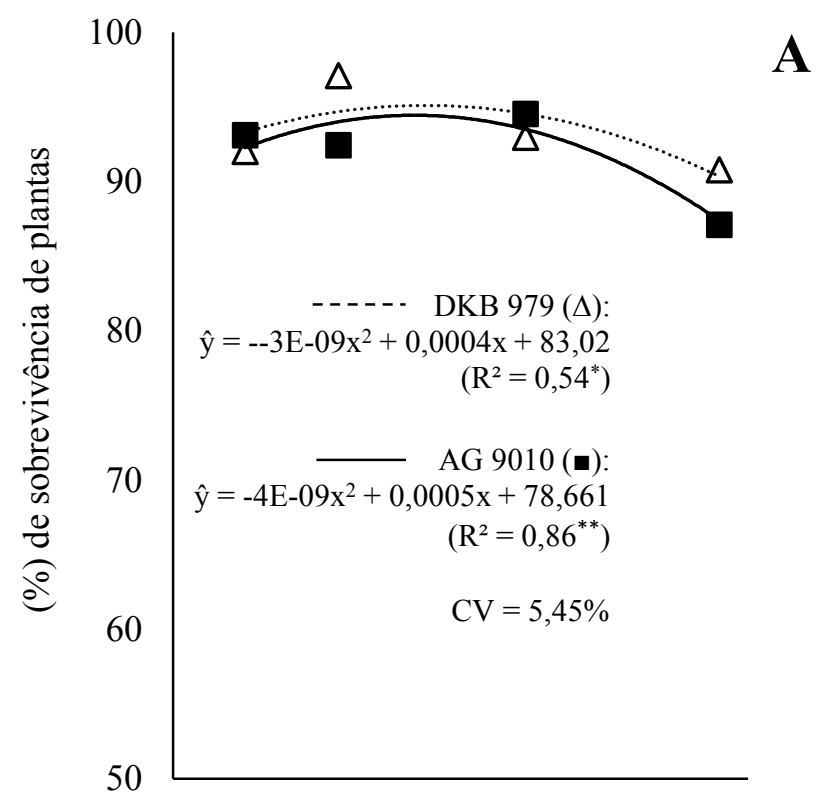

3000045000600007500090000105000

População inicial de plantas ha-1

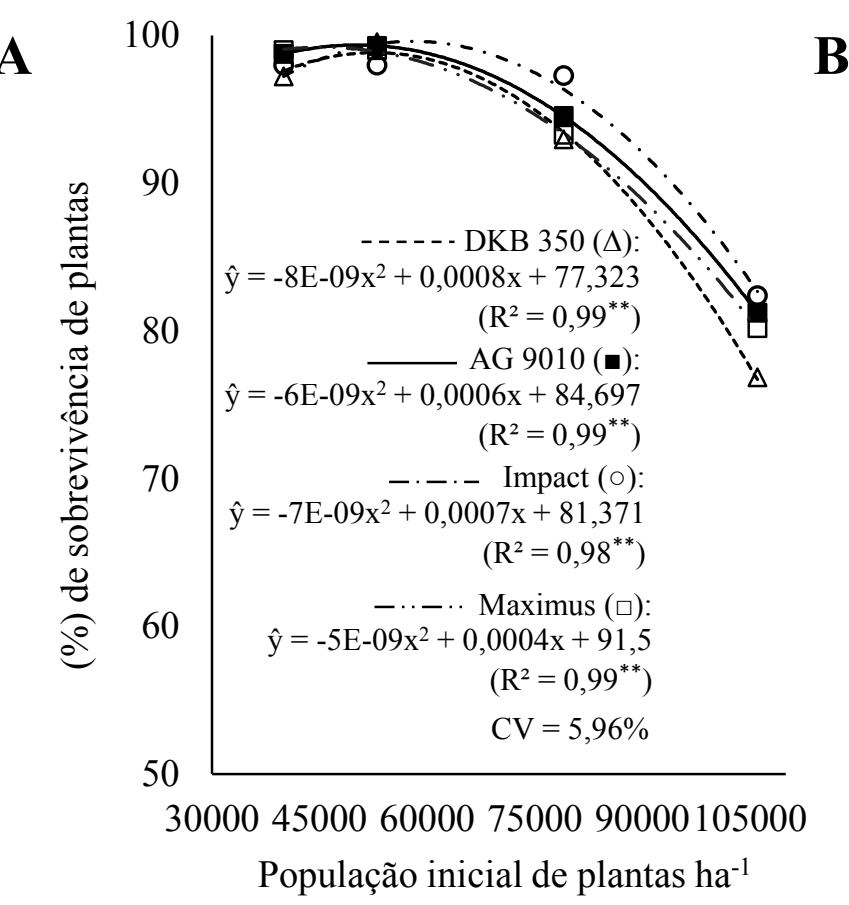

B
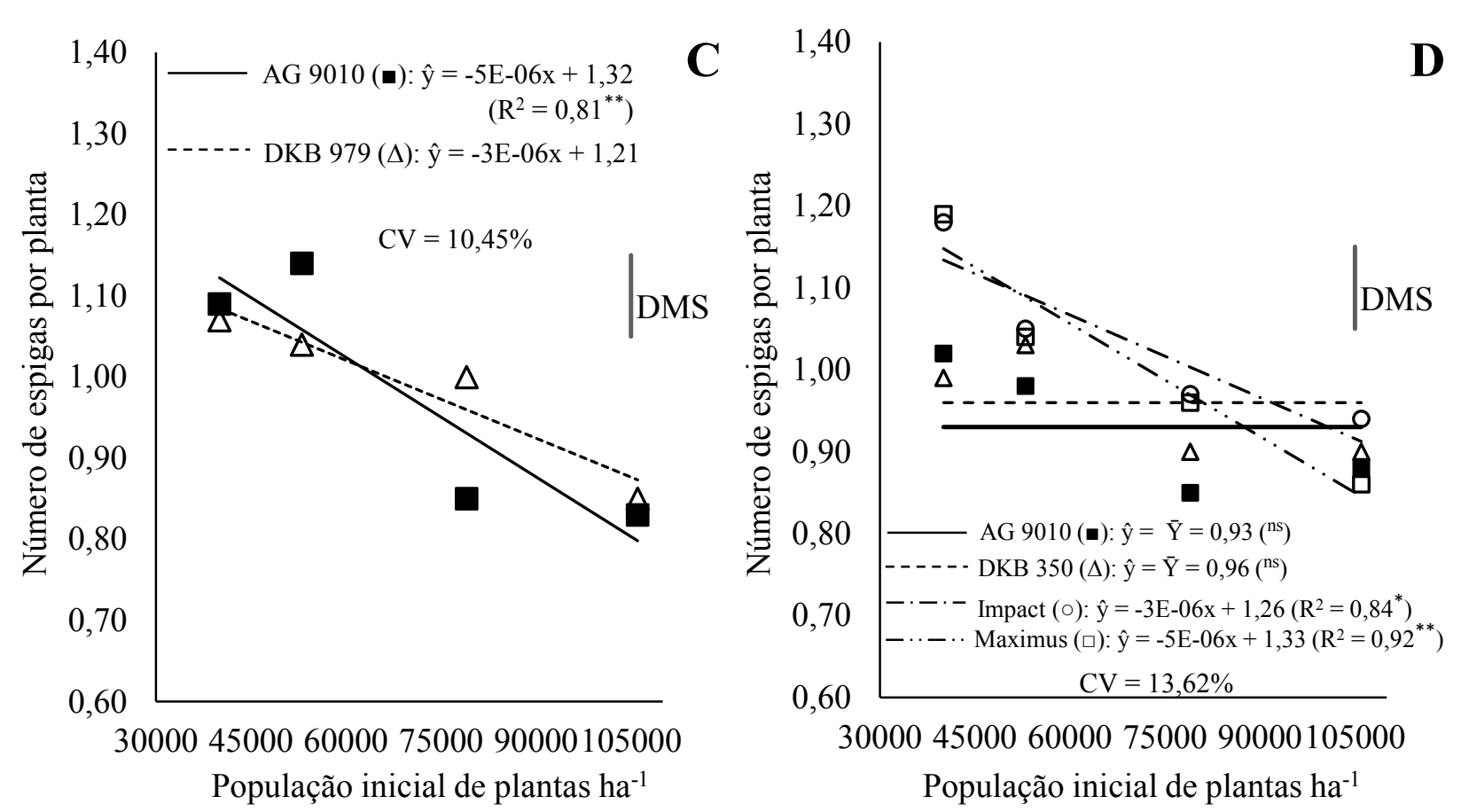

FIGURA 2. (\%) Percentagem de sobrevivência de plantas na safrinha 2005 (A) e na safrinha 2007 (B) e número de espigas por planta na safrinha 2005 (C) e na safrinha 2007 (B), para as cultivares de milho AG 9010, DKB 979, DKB 350, Impact e Maximus, em razão do aumento da população de plantas no espaçamento reduzido de $0,45 \mathrm{~m}$ entre linhas da lavoura.

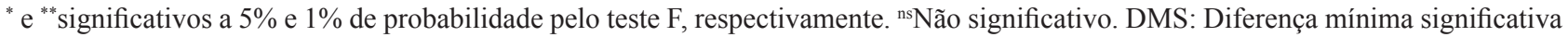
pelo teste de Tukey a 5\% de probabilidade para a interação entre cultivares x população de plantas. 
Maximus foi influenciada pela densidade populacional, havendo redução da altura das plantas desta cultivar com o aumento populacional de plantas (Figura 4B). A ausência de resposta na altura de plantas da maioria das cultivares avaliadas em função do aumento da densidade populacional corrobora com Silva et al. (2003), que também não observaram resposta de altura de plantas de híbridos de milho com incremento de plantas por área. Porém, Marchão et al. (2005) observaram maiores alturas de plantas de milho cultivado em ambiente safrinha, em razão do aumento da densidade de plantas de 33, 44 e 55 mil plantas ha-1 ${ }^{-1}$ Dourado Neto et al. (2003) estudaram dois espaçamentos entre linhas $(0,4 \mathrm{e}$ $0,8 \mathrm{~m})$ e três populações $(30,60$ e 90 mil plantas ha $\left.^{-1}\right)$ de três genótipos de milho e verificaram que a altura das plantas está relacionada com o genótipo e que, de maneira geral, o menor espaçamento, bem como a maior população, propiciaram maiores alturas de plantas. O menor porte da cultivar AG 9010, observado em ambos os anos agrícolas, deve-se ao fato desta cultivar ser de ciclo superprecoce, pois, para Almeida et al. (2000), híbridos superprecoces apresentam menor porte de plantas decorrente do menor crescimento vegetativo.

A porcentagem de plantas acamadas não foi afetada pela população de plantas em ambas as cultivares no Exp1 (Figura 3C). As duas cultivares apresentaram em média $9 \%$ de acamamento. No Exp2, apesar de não haver resposta com o aumento populacional, a menor porcentagem de acamamento foi obtida com a cultivar AG 9010, o que está relacionado ao menor porte das plantas desta cultivar (Figura 3B). Neste mesmo experimento, houve influência da população de plantas na porcentagem de acamamento de plantas nas cultivares Impact e Maximus; ambas as cultivares tiveram respostas quadráticas para este parâmetro. A máxima porcentagem de acamamento foi de 27,5 e $23 \%$ com população de 83 e 80 mil plantas por hectare, para as cultivares Impact e Maximus, respectivamente.

Com relação à resposta quadrática que resultou na redução da porcentagem de plantas acamadas das cultivares Impact e Maximus na densidade de plantas acima de 83 e 80 mil, respectivamente, possivelmente, a redução do acamamento ocorreu devido a maior sustentação física das plantas, gerada pela maior proximidade de uma planta para outra. Entretanto, Sangoi et al. (2000) e Marchão et al. (2005) observaram resposta linear do acamamento de plantas em função da densidade populacional. De acordo com Brachtvogel et al. (2009), o acamamento está ligado principalmente à diminuição do diâmetro do caule, ao aumento da altura de planta, de inserção de espiga e ao aumento da relação altura de planta/altura de inserção de espiga, observados quando eleva-se a população de plantas. Outro fator a se considerar é o genético, em que Amaral Filho et al. (2005) salientam que a cultivar AG 9010 tende a ser mais tolerante ao acamamento; além do porte menor, as características anatômicas das células e a morfologia da própria cultivar conferem maior resistência ao acamamento.

O diâmetro do caule das plantas do milho no Exp1 foi reduzido em função do aumento da população de plantas, independente da cultivar avaliada (Figura 4A). Calonego et al. (2011) também observaram redução deste parâmetro em razão do aumento da população de plantas de 45 para 75 mil plantas. Demétrio et al. (2008) observaram redução do diâmetro do caule com o aumento populacional de 30 mil para 90 mil plantas por hectare.

$\mathrm{O}$ aumento de plantas por hectare promoveu a redução linear da massa de 1000 grãos 

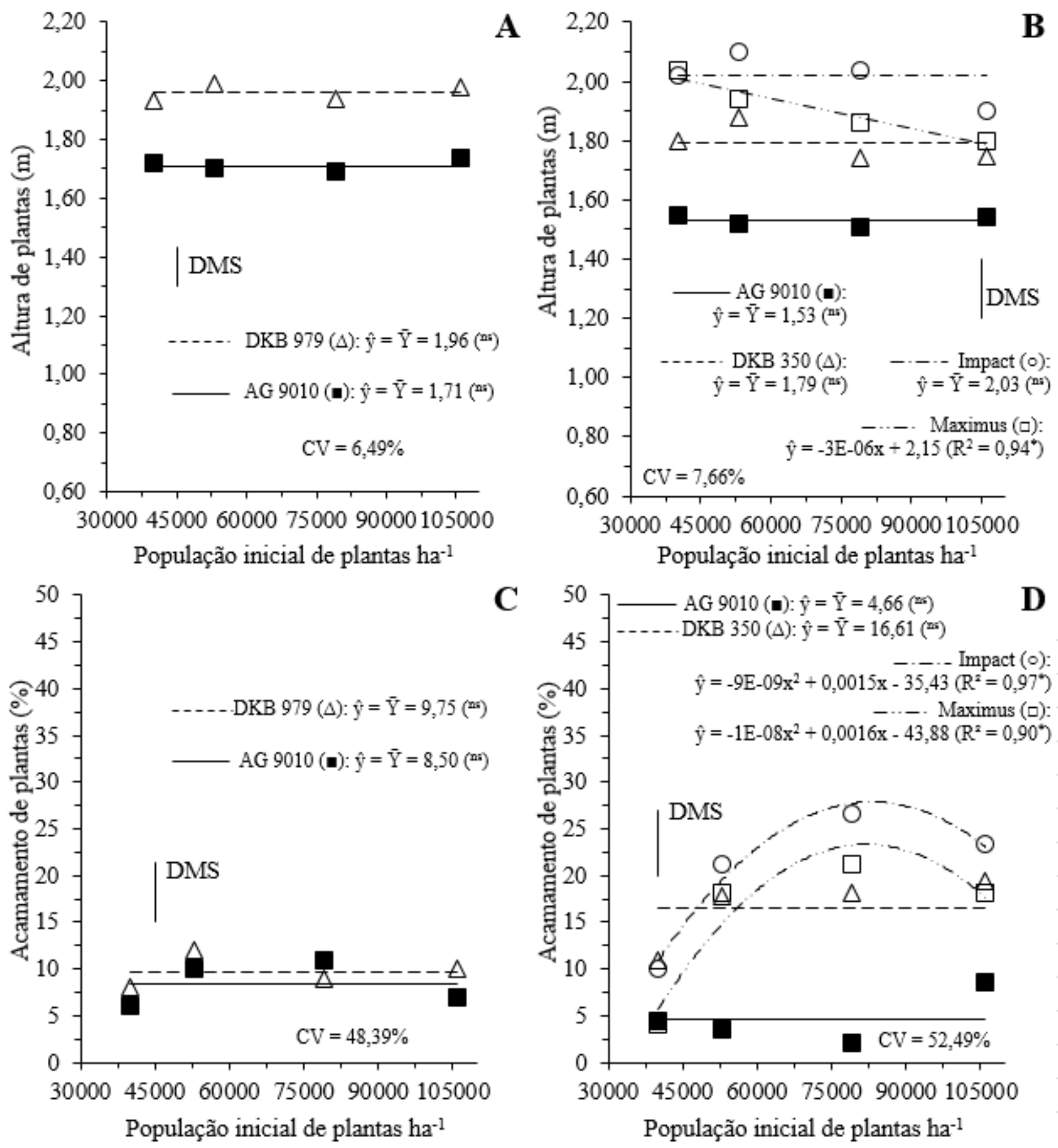

FIGURA 3. Altura de plantas na safrinha 2005 (A) e na safrinha 2007 (B) e acamamento de plantas na safrinha 2005 (C) e na safrinha 2007 (D) para as cultivares de milho AG 9010, DKB 979, DKB 350, Impact e Maximus em razão do aumento da população de plantas no espaçamento reduzido de 0,45 m entre linhas da lavoura.

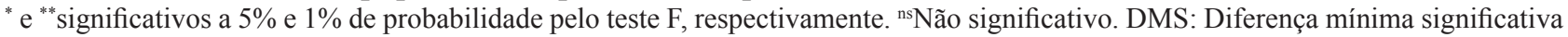
pelo teste de Tukey a 5\% de probabilidade para a interação entre cultivares x população de plantas. 
independente da cultivar avaliada no Exp1 (Figura 4B), indicando que houve maior competição intraespecífica por água, luz e nutrientes, ocorrendo assim maior partição de fotoassimilados entre as plantas (Bruns \& Abbas, 2005). Os dados obtidos estão em concordância com Pereira et al. (2008) e Flesh \& Vieira (2004), que também observaram na cultura do milho redução na massa de 1000 grãos com o aumento da população de plantas. Amaral Filho et al. (2005), avaliando a resposta do híbrido AG 9010, em razão do espaçamento entre linhas de 60 e $80 \mathrm{~cm}$, da população de plantas de 40,60 e 80 mil plantas ha-1 e das doses de nitrogênio de 0,50 , 100 e $150 \mathrm{~kg} \mathrm{ha}^{-1}$, concluíram que houve redução da massa de 1000 grãos para densidade populacional de 80 mil plantas ha-1 em ambos os espaçamentos avaliados, independente da suplementação com nitrogênio.

A produtividade apresentou resposta quadrática para as duas cultivares avaliadas no Exp 1 (Figura 5A). A máxima produtividade foi de 6.595 e $6.373 \mathrm{~kg} \mathrm{ha}^{-1}$, com população aproximada de 81 e 75 mil plantas ha ${ }^{-1}$ para cultivar AG 9010 e DKB 979, respectivamente. No Exp 2 (Figura 5B), a produtividade de grãos da cultivar AG 9010 foi de $4.887 \mathrm{~kg} \mathrm{ha}^{-1}$, não havendo interferência da densidade populacional de plantas sobre este parâmetro. Para a cultivar Impact, houve redução linear da produtividade de grãos com o aumento de plantas por hectare. Para as cultivares DKB 350 e Maximus, houve resposta quadrática da produtividade. A máxima produtividade foi de 5.974 e $5862 \mathrm{~kg} \mathrm{ha}^{-1}$, com população aproximada de 50 e 57 mil plantas ha-1, respectivamente.

Em geral, o trabalho reporta que, no cultivo de milho no ambiente safrinha no SPD do Norte do Paraná, a cultivar AG 9010 de menor porte (Figuras
3A e 3B) permite maior adensamento populacional em relação às demais cultivares semiprecoce de porte superior, como as cultivares DKB 979, Impact, Maximus e DKB 350. Segundo Farinelli et al. (2003), esta resposta pode ser atribuída ao fato de que genótipos com portes mais baixos possuem grande potencial para o cultivo adensado em razão da disposição anatômica das folhas, pois, de acordo com Almeida et al. (2000), híbridos superprecoces que apresentam menor porte de plantas decorrente do menor crescimento vegetativo, menor número de folhas e folhas mais eretas proporcionam menor competição intraespecífica, o que permite a utilização de indivíduos maiores por área, maximizando o potencial produtivo da comunidade em relação a híbridos mais tardios.

O aumento da produtividade da cultivar AG 9010 em função do aumento da população de plantas no Exp1 (Figura 5A) pode ser explicado pelo fato de o aumento do número de plantas promover o aumento no número de espigas por unidade de área, ocorrendo assim compensação da produtividade (Marchão et al., 2005). Com certa semelhança aos resultados obtidos neste estudo, Penariol et al. (2003) verificaram incremento na produção de grãos de milho com o aumento da população de plantas do híbrido AG 9010 até 80 mil plantas ha-1.

Dourado Neto et. al (2003) pesquisaram os efeitos da população de plantas e da densidade de semeadura sobre a produção de grãos em híbridos com diferentes arquiteturas de folha. $\mathrm{O}$ híbrido com arquitetura foliar ereta (DKB 911) obteve aumento da produção de grãos com o aumento da densidade populacional, de 30 para 90 mil plantas ha-1. Já nos híbridos de arquitetura foliar prostada (AG 1051) e semi-ereta (AG 7575), houve aumento no rendimento até a população de 60 mil plantas ha-1. 


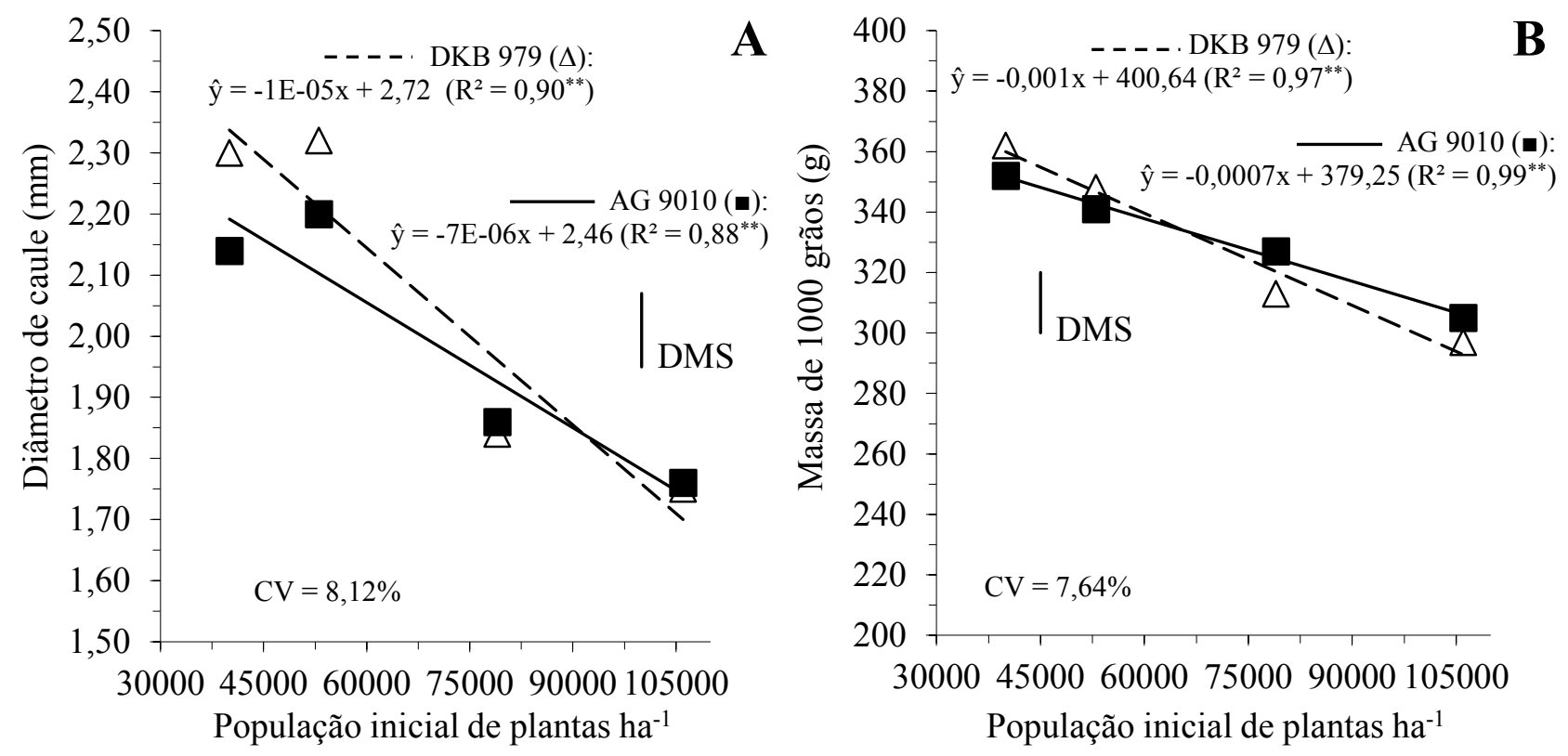

FIGURA 4. Diâmetro de caule (A) e massa de 1000 grãos (B) na safrinha de 2005, para as cultivares de milho AG 9010 e DKB 979, em razão do aumento da população de plantas no espaçamento reduzido de 0,45 m entre linhas da lavoura.

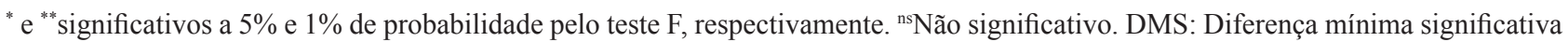
pelo teste de Tukey a 5\% de probabilidade para a interação entre cultivares x população de plantas.
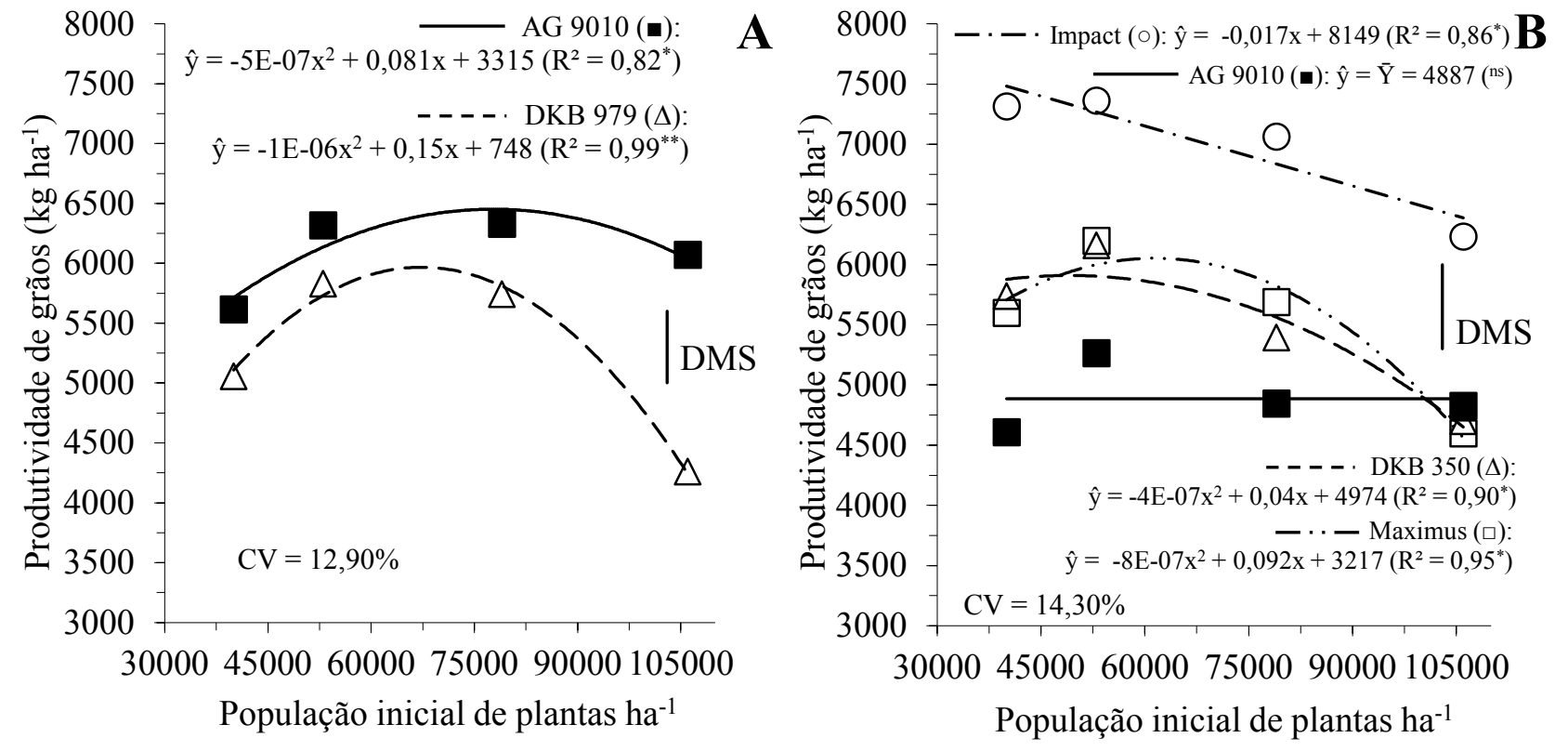

FIGURA 5. Produtividade de grãos na safrinha 2005 (A) e na safrinha 2007 (B), para as cultivares de milho AG 9010, DKB 979, DKB 350, Impact e Maximus, em razão do aumento da população de plantas no espaçamento reduzido de $0,45 \mathrm{~m}$ entre linhas da lavoura.

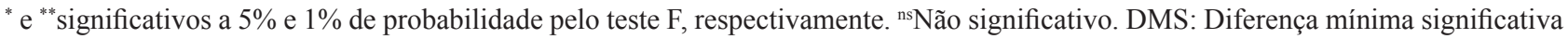
pelo teste de Tukey a 5\% de probabilidade para a interação entre cultivares x população de plantas. 


\section{Conclusões}

1. A cultivar AG 9010 respondeu significativamente ao aumento da população de plantas somente no Exp 1, atingindo máximas produtividades com cerca de 70 a 80 mil plantas por hectare, no espaçamento reduzido de $0,45 \mathrm{~m}$ na safrinha do Norte do Paraná.

2. A cultivar DKB 979 apresentou maior produtividade quando cultivada com cerca de 70 a 75 mil plantas por hectare.

3. As cultivares DKB 350, Maximus e Impacto não toleram aumento populacional de plantas, necessitando manter a recomendação tradicional de 45 a 55 mil plantas por hectare.

4. As cultivares Maximus e Impacto apresentaram maiores índices de acamamento de plantas com o aumento populacional.

\section{Agradecimentos}

À família Tamborlim, de Atalaia, PR, e à família Firmano, de Alvorada do Sul, PR, que gentilmente cederam as áreas para a realização destes experimentos, assim como prestaram total apoio de maquinário, insumos e equipe na condução dos trabalhos.

\section{Referências}

ALMEIDA M. L.; MEROTTO JÚNIOR A.; SANGOI, L.; ENDER, M. \& GUIGDOLIN, A. (2000) Incremento na densidade de plantas: uma alternativa para aumentar o rendimento de grãos de milho em regiões de curta estação estival de crescimento. Ciência Rural, 30:23-29.

AMARAL FILHO, J. P. R.; FORNASIERI FILHO,
D.; FARINELLI, R. \& BARBOSA, J.C. (2005) Espaçamento, densidade populacional e adubação nitrogenada na cultura do milho.

Revista Brasileira de Ciência do Solo, 29:467-473.

BALBINOT JÚNIOR, A. A. \& FLECK, N. G. (2005) Competitividade de dois genótipos de milho (Zea mays) com plantas daninhas sob diferentes espaçamentos entre fileiras. Planta Daninha, 23:415-421.

BRACHTVOGELI, E. L.; PEREIRA, F. R. A.; CRUZ, S. C. S. \& BICUDO, S. J. (2009) Densidades populacionais de milho em arranjos espaciais convencional e equidistante entre plantas. Ciência Rural, 39:2334-2339.

BRUNS, H. A. \& ABBAS, H. K. (2005). Ultrahigh plant populations and nitrogen fertility effectson corn in the mississippi valley. Agronomy Journal, 97:1136-1140, 2005.

CALONEGO, J. C.; POLETO, L. C.; DOMINGUES, F. N. \& TIRITAN, C. S. (2011) Produtividade e crescimento de milho em diferentes arranjos de plantas. Revista Agrarian. 4:84-90.

Conab, Companhia Nacional do Abastecimento (2013) Levantamento de safras. Disponível em: $\quad<$ http://www.conab.gov.br/olalacms/ uploads/arquivos/13_06_03_15_28_45_ boletim maio 2013.pdf $>$. Acessado em: 15 de maio de 2013.

CRUZ, J. C.; PEREIRA, F. T. F.; PEREIRA FILHO, I. A.; OLIVEIRA, A. C. \& MAGALHÃES, P. C. (2007) Resposta de cultivares de milho à variação em espaçamento e densidade. Revista Brasileira de Milho e Sorgo, 6:60-73.

CRUZ, J. C.; SILVA, G. H.; PEREIRA FILHO, I. A.; GONTIJO NETO, M. M. \& MAGALHÃES (2010) Caracterização do cultivo de milho 
safrinha de alta produtividade em 2008 e 2009. Revista Brasileira de Milho e Sorgo, 9:177-188.

DE-MARIA, I. C. e RAMOS NP (2007) Conservação e manejo do solo. In: Azevedo DMP de \& Beltrão NE de $M$ (Eds.). O agronegócio da mamona no Brasil. (2 Ed.). Campina Grande: Embrapa Algodão. Brasília: Embrapa Informações Tecnológicas, p.97-115.

DEMÉTRIO, C.S.; FORNASIERI FILHO, D.; CAZETTA, J. O. \& CAZETTA, D. A. (2008) Desempenho de híbridos de milho submetidos a diferentes espaçamentos e densidades populacionais. Pesquisa Agropecuária Brasileira. 43:1691-1697.

DOURADO NETO, D.; PALHARES, M.; VIEIRA, P. A.; MANFRON, P. A.; MEDEIROS, S. L. P. \& ROMANO, M. R. (2003) Efeito da população de plantas e do espaçamento sobre a produtividade de milho. Revista Brasileira de Milho e Sorgo, 2:63-77.

FARINELLI, R.; PENARIOL, F. G.; BORDIN, L.; COICEV, L. \& FORNASIERI FILHO, D. (2003) Desempenho agronômico de cultivares de milho nos períodos de safra e safrinha. Bragantia, 62: 235-241.

FLESCH， R. D.; \& VIEIRA, L. C. (2004) Espaçamentos e densidades de milho com diferentes ciclos no oeste de Santa Catarina. Ciência Rural, 34:25-31.

FORNASIERI FILHO, D. (2007) Manual da cultura do milho. 1. ed. Jaboticabal: funep, 273p.

LLOVERAS, J.; MANENT, J.; VIUDAS, J.; LÓPEZ, A. \& SANTIVERI, P. (2004) Seeding rate influence on yield and yield componentes of irrigated winter wheat in a mediterranean climate. Agronomy Journal, 96:1258-1265.
MARCHÃO, R. L.; BRASIL, E. M.; DUARTE, J. B.; GUIMARÃES, C. M. \& GOMES, G. A. (2005) Densidade de plantas e características agronômicas de híbridos de milho sob espaçamento reduzido entre linhas. Pesquisa Agropecuária Tropical, 35:93-101.

PENARIOL, F. G.; FORNASIERI FILHO, D.; COICEV, L.; BORDIN, L. \& FARINELLI, R. (2003) Comportamento de cultivares de milho semeadas em diferentes espaçamentos entre linhas e densidades populacionais, na safrinha.

Revista Brasileira de Milho Sorgo, 2:52-60. PEREIRA, F.R.S.; CRUZ, S.C.S.;ALBUQUERQUE, A. W.; SANTOS, J. R. \& SILVA, E. T. (2008) Arranjo espacial de plantas de milho em sistema plantio direto. Revista Brasileira de Engenharia Agrícola Ambiental, 12:69-74.

PIANA, A. T.; SILVA, P. R. F.; PREDEMEIER, C.; SANGOI, L.; VIEIRA, V. M.; SERPA, M. S. \& JANDREY, D. B. (2008) Densidade de plantas de milho híbrido em semeadura precoce no rio grande do sul. Ciência Rural, 38.

SANGOI, L.; ENDER, M.; GUIDOLIN,A. F.; BOGO, B. \& KOTHEET, D. M. (2000) Incidência e severidade de doenças de quatro híbridos de milho cultivados com diferentes densidades de plantas. Ciência Rural, 30:17-21.

SANGOI, L.; ALMEIDA, M. L.; SILVA, P. R. F. \& ARGENTA, G. (2002) Bases morfofisiológicas para maior tolerância dos híbridos modernos de milho a altas densidades de plantas. Bragantia, 61:101-110.

SILVA, P. R. F.; ARGENTA, G. \& SANGOI, L. (2003) Fatores determinantes da escolha da densidade de plantas em milho. In: Reunião técnica catarinense de milho e feijão, 4, Lages, SC. Resumos expandidos. 25-29p. 
STRIEDER, M. L.; SILVA, P. R. F.; ARGENTA, G.; RAMBO, L.; SANGOI, L.; SILVA, A. A. \& ENDRIGO, P. C. A. (2007) Resposta do milho irrigado ao espaçamento entrelinhas depende do híbrido e da densidade de plantas. Ciência Rural, 37:634-642.
VIEIRA JÚNIOR, P. A.; DOURADO NETO, D.; BERNARDES, M. S.; MANFRON, P. A. \& MARTIN, T. N. (2006) Metodologia para estimativa de área foliar de genótipos de milho. Revista Brasileira de Milho e Sorgo. 5:182191. 